\title{
Programa de apoio a erradicação do trabalho infantil do município de Alexânia - Goiás
}

\author{
Neide Gomes de Oliveira ${ }^{1}$; Neila Maria Mendes Borges ${ }^{2}$; Maisa \\ Pires Pacheco ${ }^{3}$; Maristela Vicente de Paula 4
}

\section{Resumo}

A temática dos direitos humanos da criança e adolescente envolve conhecimentos e áreas de atuação interdisciplinares, que pedem uma formação urgente para agentes que atuam no sistema de garantias, na tarefa de formar a rede de proteção desse grupo social, sejam eles profissionais da educação, da saúde, assistência, social, justiça, segurança pública ou dos seguimentos de representação e participação popular. Este trabalho tem como objetivo apresentar o perfil dos jovens e adolescentes que vivenciam o programa denominado, Programa de Convivência e Fortalecimento de Vínculos do município de Alexânia-GO, no período que compreendeu os anos de 2014 e 2015 e, especificamente: a) discutir as política públicas de erradicação do trabalho infantil; b) caracterizar o seviço de convivência e fortalecimento de vínculo; c) identificar os aspectos sociodemográficos e socioeconômicos; d) apresentar a configuração familiar e a situação

Especialista em Direitos Humanos da Criança e Adolescente.Universidade Federal de Goiás/ Regional Catalão. Catalão-GO. Brasil. Email: neidegomes.oli@hotmail.com. 2

Mestre em Educação Física. Professora no curso de Educação Física da Universidade Federal de Goiás. Catalão-GO. Brasil. Email: neilamariamendes@gmail.com 3

Acadêmica do curso de Especialização em Planejamento, Implementação e Gestão em EaD (PIGEAD) na Universidade Federal Fluminense. Rio de Janeiro. Brasil. Email: pachecoricioli@gmail.com

4

Mestre em Educação Física. Professora no curso de Educação Física da Universidade Federal de Goiás. Catalão-GO. Brasil. Email maristela.vicente.paula@gmail.com 
educacional dessas crianças e adolescentes usuários do programa. A metodologia utilizada, foi a pesquisa de campo do tipo exploratória e descritiva realizada através de entrevista semiestruturada com a Assistente Social responsável. Os resultados sinalizam que o Serviço tem sido uma ótima alternativa encontrada para resgatar crianças em situação de abandono, ou de risco social e também, uma das melhores alternativa para garantir a continuidade de seu desenvolvimento e integridade física e psíquica.

Palavras Chave: trabalho infantil; direitos humanos; interdisciplinaridade. 